\title{
Construcción concisa.
}

\section{El proceso de la obra del Pabellón de los Países Nórdicos en la Bienal de Venecia de Sverre Fehn (1958-1962)}

María Dolores Sánchez Moya, Ángel Luis Fernández Campos*

Resumen / Abstract pág 51 | Bibliografía pág 53

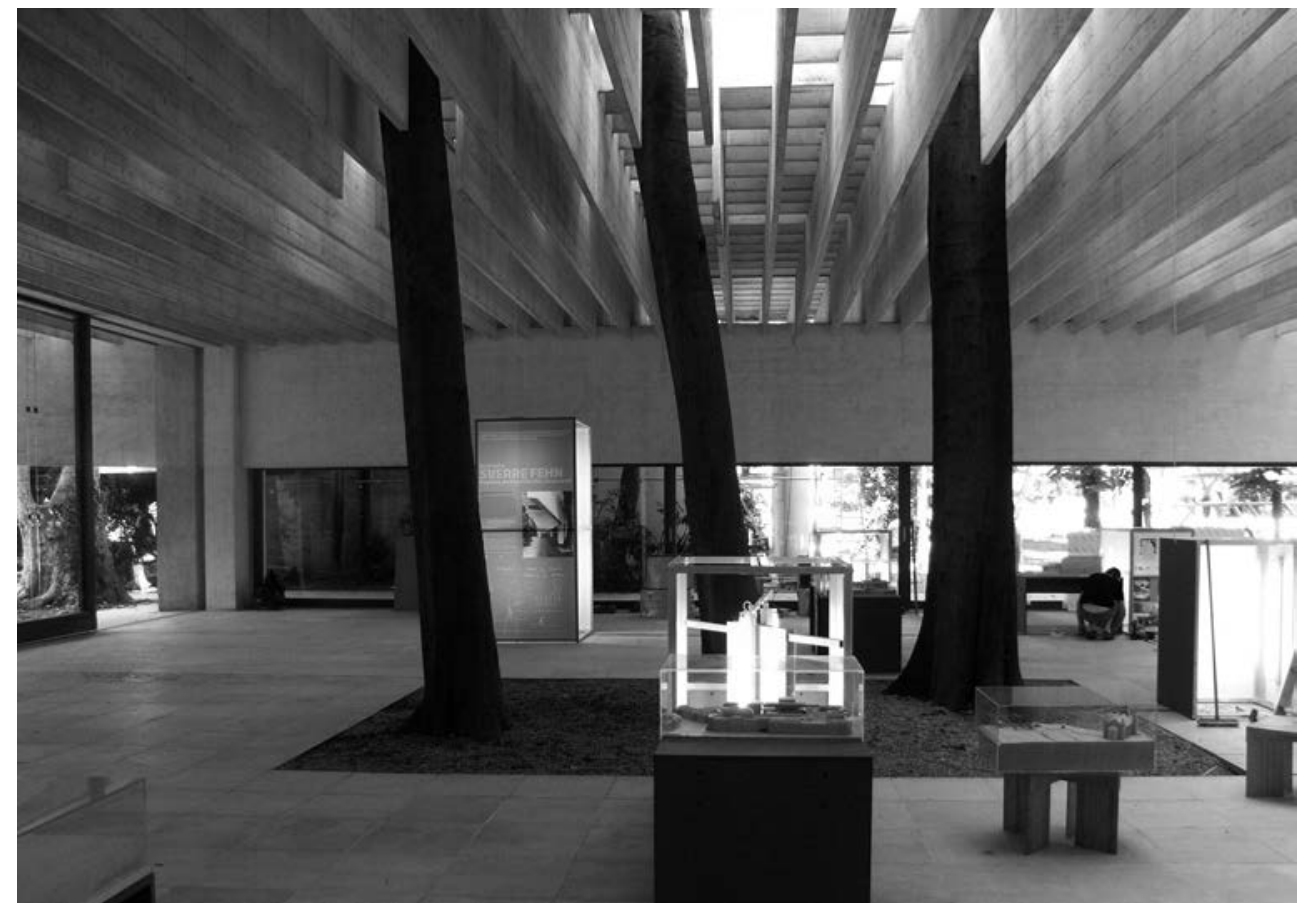

Palabras clave

Sverre Fehn

pabellón

Venecia

construcción

filtro

luz

La arquitectura de Sverre Fehn se caracteriza por afirmar la construcción como el soporte del proyecto, por la capacidad expresiva de la unión entre las piezas y por la importancia otorgada a las cualidades de la materia. Fehn manifiesta de forma repetida en sus escritos y entrevistas su convicción acerca de la indivisibilidad de la construcción y la arquitectura. Son numerosas las alusiones al pensamiento sobre la construcción en sus escritos y entrevistas. En la base de esta convicción se encuentra la formación de un joven Fehn, colaborador de Jean Prouvé en París ${ }^{1}$, interesado en las arquitecturas anónimas del Norte de África y Japón y el poso de la construcción tradicional noruega.

El Pabellón de los Países Nórdicos en la Bienal de Venecia representa un ejemplo paradigmático de la idea de correspondencia entre espacio y construcción. En esta obra se hace evidente una característica que acompaña la obra del arquitecto noruego: a la arquitectura se llega a través de la claridad de la construcción y el empleo de los elementos exactos. Tanto en el pabellón de Bruselas como en el de Venecia el proyecto gira en torno al planteamiento de un sistema constructivo conciso y lógico; breve en elementos, la expresión de un espacio con exactitud. Tanto es así que han sido descritos como "preconstrucciones más que edificios".

Este artículo sintetiza algunos aspectos desarrollados en la tesis doctoral "El Pabellón de los Países Nórdicos en la Bienal de Venecia de Sverre Fehn: la cubierta filtro: sol, árboles, sombra".3 Aunque el Pabellón está considerado como una de las más importantes obras en la trayectoria de Sverre Fehn, no ha sido objeto de un estudio en profundidad. Son numerosos los artículos y capítulos de libros que la describen, pero no se ha publicado ninguna monografía dedicada a la sede nórdica. Los aspectos especialmente desconocidos han sido el sistema y el proceso constructivo. No existe ninguna publicación que aborde este tema puesto que los documentos relativos a la construcción (planos, fotografías, informes de obra y correspondencia) han permanecido inéditos y repartidos en distintos archivos. Incluso las referencias al sistema

\footnotetext{
${ }^{1}$ Entrevista de Armelle Lavalou a Sverre Fehn; A.L: "Jean Prouvé afirma la predominancia de la construcción en la arquitectura. ¿No le parece demasiada racionalidad?". S.F: "Al contrario. Jean Prouvé era un poeta de los materiales. Asimismo, podemos suscribir la frase de Perret: ,La construcción es una lengua materna, la arquitectura, una lengua eterna', para mi sin construcción no hay arquitectura. El punto de partida de la construcción es el equilibrio entre un pensamiento y su lenguaje. La historia y su estructura son indisociables. La idea poética necesita el soporte de una estructura para existir". Lavalou, Armelle; "Au pays des lumières horizontales, un entretien avec Sverre Fehn", págs 83-85. Norberg-Schulz, Christian; "Une vision poètique", L'Architecture Aujourd'hui, nº 287, Junio, 1993, págs 91-93. (Número monográfico: Sverre Fehn).

2 "Hasta un cierto punto es cierto que la idea de la construcción guia todos los proyectos de Fehn. Donde probablemente se puede apreciar esto con más claridad es en sus museos, algunos de ellos son más preconstrucciones que edificios". Holmebakk, Carl-Viggo; "Visiting Fehn's Houses", A+U, n³40, 01:1999, págs 93-99. (Número monográfico: Sverre Fehn, above and below the horizon)

${ }^{3}$ María Dolores Sánchez Moya; "El Pabellón de los Paises Nórdicos en la Bienal de Venecia de Sverre Fehn: la cubierta filtro: sol, árboles, sombra", Tesis doctoral desarrollada en el programa de doctorado del Departamento de Proyectos Arquitectónicos de la ETSAM y leída el 6 de
} noviembre de 2012. 
[1] Pabellón de los Países Nórdicos en la Bienal de Venecia. La estructura de vigas de cubierta se interrumpe puntualmente para dejar crecer a los Feles que viven en su interior. Autor: Angel Luis Fernández Campos, 2008

[2] Transmisión y reflexión de la luz a través del filtro de cubierta del Pabellón de los Países Nórdicos. Autor: Mª Dolores Sánchez Moya, 2011 constructivo se han publicado en alguna ocasión con imprecisiones y errores. ${ }^{4} \mathrm{~A}$ lo sumo, se ha publicado la descripción de los materiales que componen la obra y el detalle constructivo de la unión de los canales de desagüe de cubierta a las vigas. ${ }^{5}$

$\mathrm{Si}$, como se ha afirmado antes, la construcción es el soporte conceptual del proyecto en muchas de las obras de Fehn y especialmente en el Pabellón, la escasez e imprecisión en lo referente al sistema y proceso constructivo de la obra en la difusión de la obra, hace que lo publicado esté desprovisto de un aspecto fundamental para su completa comprensión.

Las fuentes originales se encuentran repartidas entre varios archivos, siendo los más relevantes el Archivo Nacional de Suecia y el archivo personal de Fredik Fogh ${ }^{6}$, arquitecto codirector de la obra junto con Fehn. Suecia tuvo un papel fundamental en la iniciativa y desarrollo de la sede nórdica, y su gobierno ha conservado los planos de todas las fases del proyecto, los informes y la correspondencia entre todas las partes implicadas en la obra. El planteamiento del proceso constructivo que aquí se narra es una síntesis de los datos obtenidos en las fuentes inéditas y que se ha contrastado y verificado en una entrevista con Fredik Fogh.

\section{El umbráculo de Venecia}

La sede nórdica en Venecia es una arquitectura que se define por su cubierta, un tamiz denso de vigas de hormigón superpuestas con una disposición ortogonal, que se interrumpe puntualmente para permitir el paso de los árboles que viven en su interior [1]. La distancia de separación entre las vigas $-0,523 \mathrm{~m}$ - y su canto $-1 \mathrm{~m}-$, se establecen con el objetivo de bloquear la luz directa del sol. De esta forma, los dos estratos de vigas generan un filtro de dos metros de espesor que produce un plano de iluminación difusa en el interior [2]. Esta configuración de la cubierta pretende resolver los dos condicionantes principales del proyecto: la creación de un espacio expositivo flexible y la preservación de los árboles de mayor porte. ${ }^{7}$

La repetición modular de la planta del Pabellón nace del ritmo impuesto por las vigas [3]. La superposición de los dos estratos del umbráculo de hormigón forma una retícula de base cuadrada que se traslada al resto del edificio. Los elementos del edificio se dimensionan y se organizan en la planta de acuerdo a esta pauta que se rige por dos órdenes: un módulo cuadrado de 0,523 metros de lado y otro superior que engloba siete módulos base, de 3,66 metros de lado. Todos los elementos que integran el Pabellón e incluso los despieces de los encofrados están dimensionados según este sistema de doble módulo.

La estructura portante se sitúa concentrada en el perímetro de la planta con el objetivo de proporcionar una superficie de $400 \mathrm{~m}^{2}$ despejada y libre de soportes, al servicio de la flexibilidad del espacio expositivo. La planta rectangular se cierra en dos de sus lados hacia el ángulo ciego del solar mediante dos muros de hormigón que forman una L [4]. El interior se abre hacia el parque en las otras dos fachadas que completan el rectángulo. Un formidable dintel de dos metros de canto salva la luz de más de 25 metros entre uno de los muros y el único pilar del Pabellón, y permite una continuidad física y visual completa de la exposición con la plaza de ceremonias del recinto de la Bienal.

\section{Intérpretes}

Sverre Fehn, tras ganar el concurso restringido de ideas y desarrollar el proyecto del Pabellón, fue designado por el comité nórdico ${ }^{8}$ para organizar la licitación de la obra, estudiar las ofertas y seleccionar al arquitecto local que colaboraría en la dirección. La obra fue adjudicada a la Todeschini. Se establece la recepción provisional de la obra el 1 de marzo de 1962, a fin de poder organizar convenientemente la participación en la Bienal de ese año. La dirección facultativa recae a efectos legales en el arquitecto Fredrik Fogh y el ingeniero Bregani, pero Fehn y Neegard también asumen el papel de directores facultativos y trabajan en estrecha colaboración con Fogh, que les mantiene al corriente en todo el proceso. El equipo noruego realiza cinco visitas de obras documentadas en el plazo de un año hasta la recepción provisional en junio de 1962.

\section{Arranque}

La primera decisión se centra en el material predominante en el edificio: el hormigón blanco. Durante el mes de julio Todeschini ha realizado pruebas con el fin de decidir con qué composición

\footnotetext{
${ }^{4}$ Kenneth Frampton se refiere a las vigas de hormigón pretensado del Pabellón cuando en realidad se ejecutaron con homigón in situ "the bold counterchanging roof structure, consisting of light prestressed roof members running in one direction and lighter prestressed brise-soleil purlins running in the other (...)". Per Olaf Fjeld, Sverre Fehn; The thought of construction, Rizzoli, Nueva York, 1983, pág 11.

$\mathbf{5}$ La revista que recoge la primera y más completa publicación sobre la obra recién terminada del Pabellón, es la publicación periódica noruega Byggekunst. Una fotografía desde el exterior del edificio ilustra la cubierta de la revista. El artículo dedica once páginas a la publicación de varios planos que integran el proyecto de ejecución y varias de las imágenes del reportaje realizado por Feruzzi.

La descripción que acompaña el artículo se repetirá en publicaciones posteriores sobre esta obra. La importancia de este documento se basa en la difusión de la planta completa -plano 10-y el detalle constructivo de la cubrición del pabellón -plano 15-. La planta se volverá a publicar completa en pocas ocasiones y a un tamaño mucho más reducido; en revistas y monografías se suele omitir la información de los ejes y las cotas. El plano 15 volverá a publicarse en la revista Arkitecktur (1963) y Spacio \& Societá (1980) pero a un tamaño en el que resulta ilegible la leyenda de materiales que forman la cubrición. El artículo recoge fotografías de la exposición que inaugura el Pabellón en junio de 1962. Fehn, Sverre; "Nordisk paviljong ved Biennalen I Venezia", Byggekunst, $n^{\circ} 6$, Junio, 1962, págs 145-155. (Traducido al inglés en: Yvenes, Marianne y Madshus, Eva, (ed.); Architect Sverre Fehn, Intuition, Reflection, Construction, Nasjonal Museet for Kunst, Arkitektur og Design Oslo, 2008, págs 46-49)

${ }^{6}$ El arquitecto Fredrik Fogh nació en Copenhague en 1923. Cuando Fehn finaliza el proyecto de ejecución, Fogh se encontraba dirigiendo las obras de ampliación del vecino pabellón danés, lo que favoreció su elección como arquitecto co-director del pabellón nórdico. Actualmente continúa residiendo en Milán. Los datos sobre cómo tomó parte en la obra los ha proporcionado él mismo en una entrevista realizada para la tesis de María Dolores Sánchez Moya en Milán el 23 de diciembre de 2009.

${ }^{7}$ La gerencia de la Bienal protegía en concreto dieciocho ejemplares, de los cuales Fehn conserva diez: ocho almeces, un abedul blanco y el gran plátano de la avenida.

${ }^{8}$ Un comité nórdico, heredero del comité que organizó el concurso, se constituyó para que representantes de los gobiernos de Noruega, Finlandia y Suecia figurasen como representantes de la propiedad durante el desarrollo de las obras.
} 

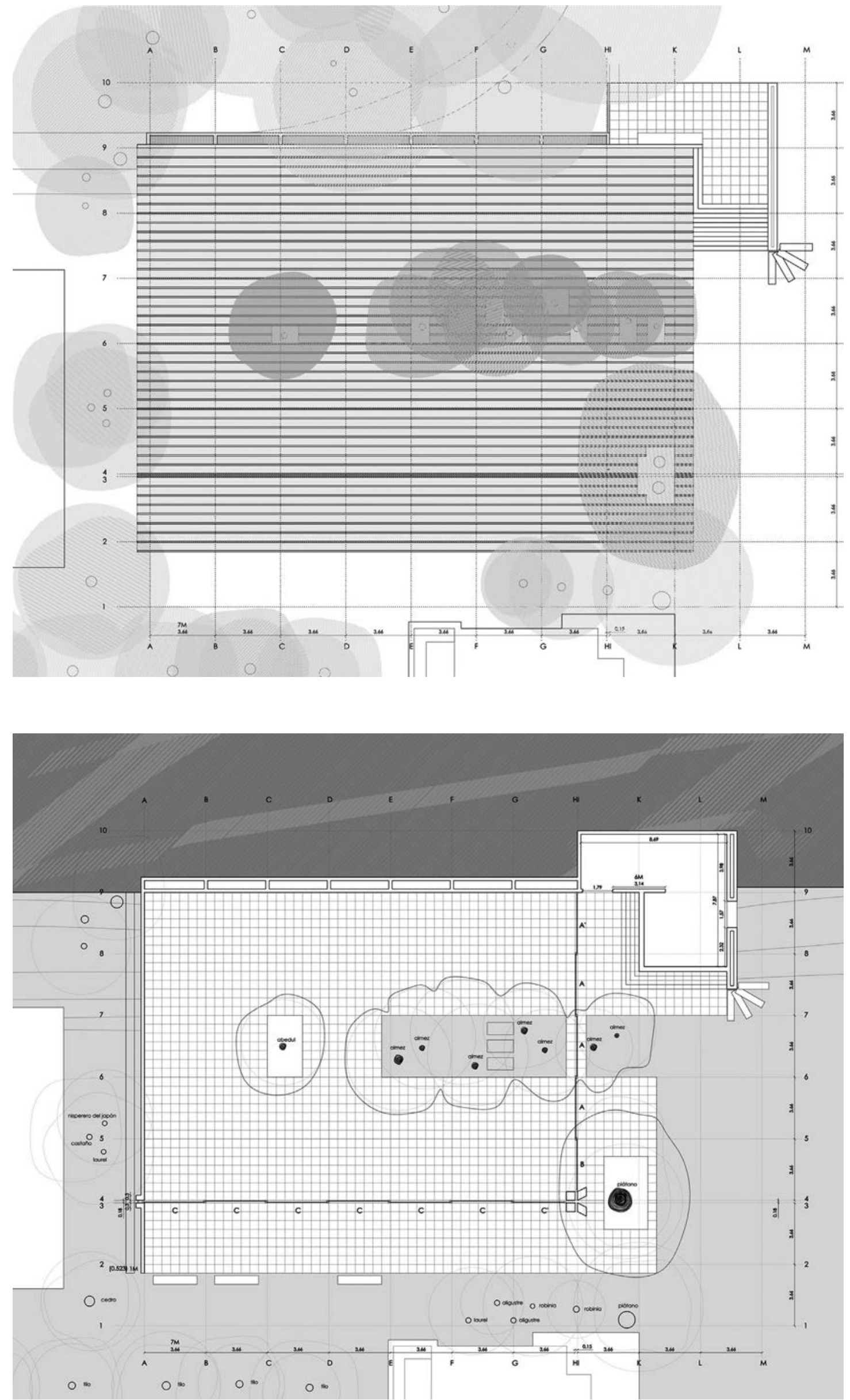
se fabricaría, ya que en el pliego no se habían concretado los componentes y se contemplaban varias opciones. El comité decide ejecutar todo el hormigón visto con cemento blanco, árido y arena de mármol blanco, con un eventual añadido de arena blanca. Esta composición del hormigón permitiría aumentar su capacidad de reflexión de la luz de un $40 \%$ a un $45 \%$.

El estudio geotécnico realizado en el comienzo de la obra9 revela que el terreno es peor de lo esperado, por lo que fue necesario reforzar la cimentación prevista en el proyecto.

Los muros y el pilar arrancan de la cimentación y se levantan en una primera fase de hormigonado hasta una cota de 2,40 metros, [5] que es la altura de imposta del dintel y la altura de talud que contiene el muro de contención. El muro de contención es doble, unido por contrafuertes de hormigón que coinciden con el módulo de 3,66 m. Cuando el doble muro supera la cota de coronación del talud, se levanta solo el muro interior. Durante el mes de noviembre, se construye el segundo tramo del muro más corto hasta su cota de coronación $-5,30$ metros- y el dintel. Los dos elementos se hormigonan simultáneamente. Al mismo tiempo, se termina el segundo tramo del muro largo hasta su coronación -4,30 metros-, salvo la parte que delimita el almacén que se levanta con posterioridad. Antes de comenzar diciembre se está en disposición de comenzar con la cubierta. En este momento, la obra sigue el ritmo previsto para acabar en plazo. ${ }^{10}$

\section{La gran viga ha salvado el árbol}

Sobre el muro lateral y el pilar se construye el dintel de dos metros de canto y 0,75 de espesor, conformado como una doble viga de hormigón que aloja los raíles del cerramiento de puertas correderas [6]. Tanto el dintel como el muro longitudinal constituyen los apoyos principales de la primera capa de vigas de cubierta. En la ejecución del dintel tiene una enorme importancia la apertura en su desarrollo para esquivar el plátano centenario que forma parte del arbolado de alineación de la avenida principal. Este árbol representa el ejemplar de mayor porte del solar, y el elemento dominante en la organización de la planta y la imagen del conjunto. La posición de su tronco es el origen de los ejes principales de la planta a partir de los cuales se origina toda la retícula modular de la cubierta. La construcción de este elemento se revela como un hito importante en la obra, dado que durante la visita de Fehn y Neegard del 10 y 11 de diciembre de 1961, toman una fotografía [7] en la que se aprecia que el dintel y el pilar están totalmente terminados. Esta fotografía es enviada a la propiedad, con el siguiente texto: "esta imagen muestra cómo la gran viga ha salvado el árbol". ${ }^{11}$ Esta fotografía es la única que se envía en todo el transcurso de la obra.

\section{Parece que hemos tenido suerte con la luz}

La ejecución de la cubierta supone la misión más compleja de la obra. La intención que ha perseguido todo el proyecto del Pabellón es que las vigas sean lo más esbeltas posibles. En el proyecto básico Neegard había establecido un espesor de cuatro a cinco centímetros que tuvo que ser ampliado hasta seis en el proyecto de ejecución.

Antes del comienzo de los trabajos en Venecia, Fehn y Neegard se trasladaron a Dinamarca para supervisar la fabricación de un prototipo de vigas de cubierta y comprobar que era viable la esbeltez prevista. La empresa Larsen \& Nielsen ${ }^{12}$ consiguió fabricar un prototipo que resultó satisfactorio para Fehn y Neegard, como recoge el pliego: "se ha realizado un elemento experimental en Copenhagen con éxito". ${ }^{13}$ Tanto los planos del proyecto de ejecución como el pliego recogen la construcción in situ de las vigas, aunque según recuerda Sverre Fehn en algún momento se planteó que pudieran ser prefabricadas. ${ }^{14}$

Neegard redacta un informe que describe las particularidades de la cubierta para que sean tenidas en cuenta a la hora de construirla. Advierte que la capa superior de vigas tan solo soportará su propio peso y el de los canales de desagüe de la cubierta. También está calculada para resistir algunos esfuerzos puntuales: la caída de alguna rama y el peso de la capa inferior de vigas, en aquellos casos en los que deban cortarse para el paso de algún árbol. En su cálculo también se ha tenido en cuenta la resistencia al pandeo debido a su longitud.

El invierno de 1961 fue excepcionalmente frío en Venecia. Durante la madrugada se alcanzaban temperaturas bajo cero. Las heladas comprometían el correcto curado del hormigón, por lo que Neegard, en la visita de diciembre, indica que debe incluirse un aditivo anticongelante en el hormigón y que las vigas deberán cubrirse con plásticos durante su fraguado. A pesar de las dificultades, el ingeniero informa que los encofrados, el armado de

\footnotetext{
${ }^{9} \mathrm{Al}$ no poderse realizar estudios geotécnicos con anterioridad, Fehn y Neegard calculan la cimentación en base a los estudios realizados para otros pabellones del recinto. La cimentación se describe en los planos 110 y 111 del proyecto de ejecución. Se calcula en base a una resistencia del terreno de $1 \mathrm{~kg} / \mathrm{cm}^{2}$. El suelo en los jardines de la Bienal era un terreno antiguo de cerca de cuatrocientos años formado por relleno de escombro. El nivel freático estaba situado entre 1,6 y 2 metros y no puede drenarse, ya que son aguas perennes. Parece que esta referencia es suficiente para Neegard y Fehn que diseñan una cimentación que baja a una cota de 1,50 m. Los datos sobre la composición del suelo se los traslada el abogado Chiodo, intermediario entre la gerencia de la Bienal y la propiedad, a Göran Göransson, secretario del comité nórdico, mientras se estaba redactando el proyecto básico el 23 de Mayo de 1959.

${ }^{10}$ Carta de Sverre Fehn a Göran Göransson, secretario del Comité Nórdico, el 21 de noviembre de 1961. Archivo Nacional de Suecia, sede Marieberg.

11 Esta imagen figura en las cartas enviadas a Göran Göranson por Fehn y Neegard en cartas por separado con fecha 21 de diciembre de 1961 Archivo Nacional de Suecia, Riksarkivet sede Marieberg.

12 Entre la documentación recopilada de la obra figura una factura del prototipo emitida por la empresa.

13 Pliego de condiciones de la obra, "Capitolato speciale e descrizione della opere murarie ed affini", pág 14. Archivo Nacional de Suecia, sede Arninge

14 En una entrevista en la que Fehn habla acerca de la ejecución artesanal de las obras, recuerda que el Pabellón de Venecia fue diseñado para que pudiera construirse prefabricado o en el sitio, dependiendo del coste global de la obra. Norri, Marja Riitta; "About Rationalism of Spiritual Content", Arkkitehti, Abril, 1986. Consultado el artículo recopilado en la monografia: Norberg-Schulz, Christian / Postiglione, Gennaro; Sverre Fehn, opera completa, Electa, Milán, 1997, pág 250. ( $2^{\mathrm{a}}$ edición, revisada y ampliada 2007)
} 

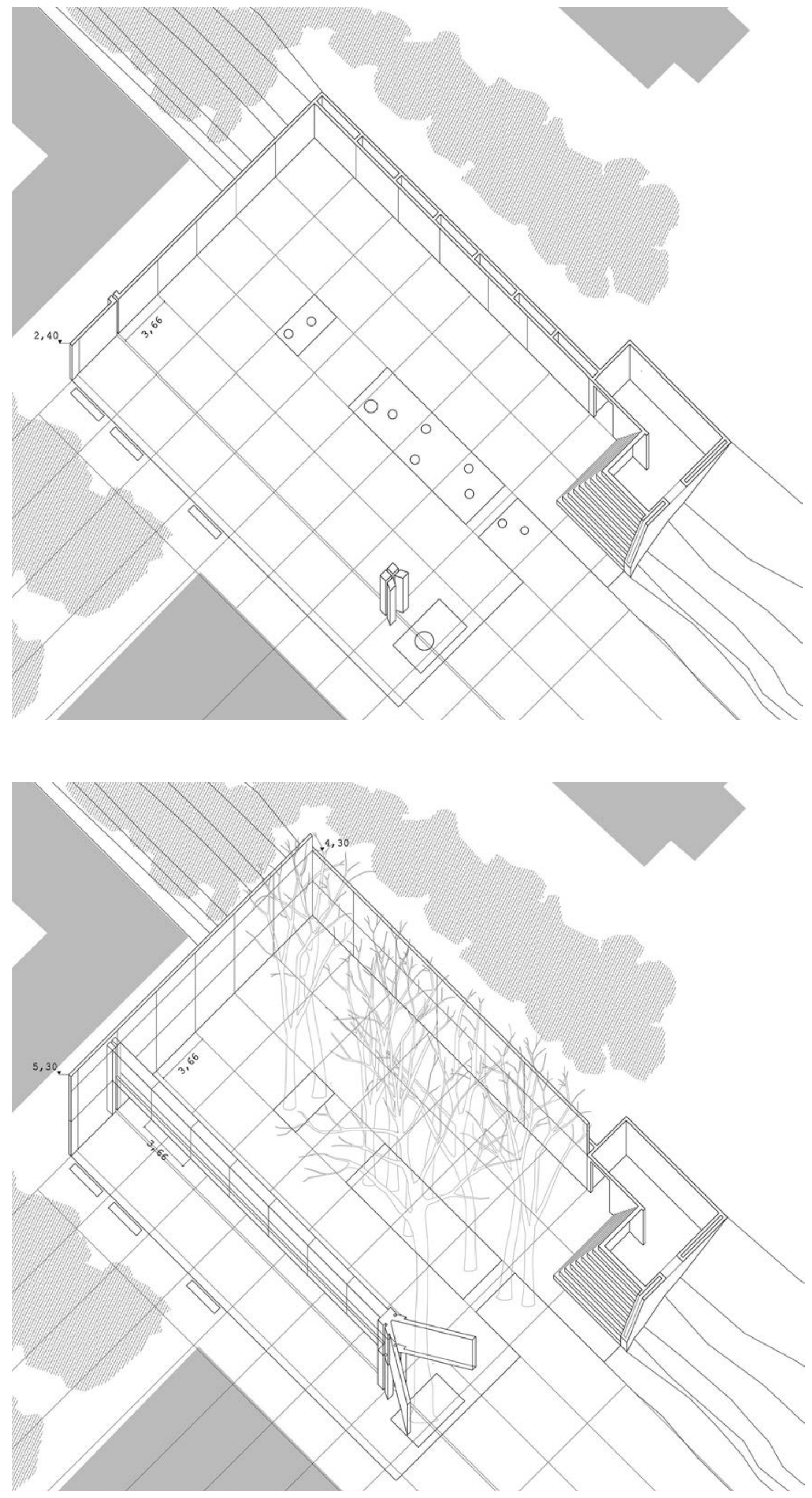

imposta del dintel $(2,40 \mathrm{~m}$.$) . Autor: \mathrm{M}^{\mathrm{a}}$ Dolores Sánchez Moya, 2012.

[6] Segunda y tercera fase de hormigonado. Dintel y coronación del muro lateral. Autor: $\mathrm{M}^{\mathrm{a}}$ Dolores Sánchez Moya, 2012.
[7] Finalización del dintel y comienzo de hormigonado de las vigas de cubierta. Autor: Desconocido. Puede ser tanto Sverre Fehn, como Arne Neegard 1961. Archivo Nacional de Suecia, Are Neegard, las vigas y el vertido del hormigón es más satisfactorio de lo previsto. Lo atribuye a la empresa constructora, muy implicada en la buena ejecución de la obra, y a la eficaz labor supervisora del arquitecto Fogh.La ejecución de la cubierta fue un proceso completamente artesanal. Las vigas se encofraron sobre listones de madera [8] que abarcaban el ancho de la viga más el espesor de los tablones laterales que conformaban el molde. Los encofrados laterales eran tableros sencillos compuestos por tablas de las mismas dimensiones que el resto de los elementos del hormigón. Las vigas se hormigonaban una a una y se vibraban a mano. Tenían el espesor mínimo establecido por los criterios constructivos: $6 \mathrm{~cm}-2 \mathrm{~cm}$ de armadura y $2 \mathrm{~cm}$ de recubrimiento a cada lado-, por lo que se empleó una antigua pala de amasar el pan para introducir bien el hormigón en el encofrado y entre los intersticios de las armaduras.

La primera capa de vigas - sustentante- penetraba diez centímetros en la coronación del dintel y se empotraba en el muro paralelo al talud. Una de cada siete vigas, coincidiendo con el módulo de 3,66 m, recrece varios centímetros para sujetar las vigas de la capa superior y así limitar el movimiento debido a su longitud [10]. En las uniones entre vigas y el dintel se situaba un gancho de acero que unía las armaduras de ambas piezas.

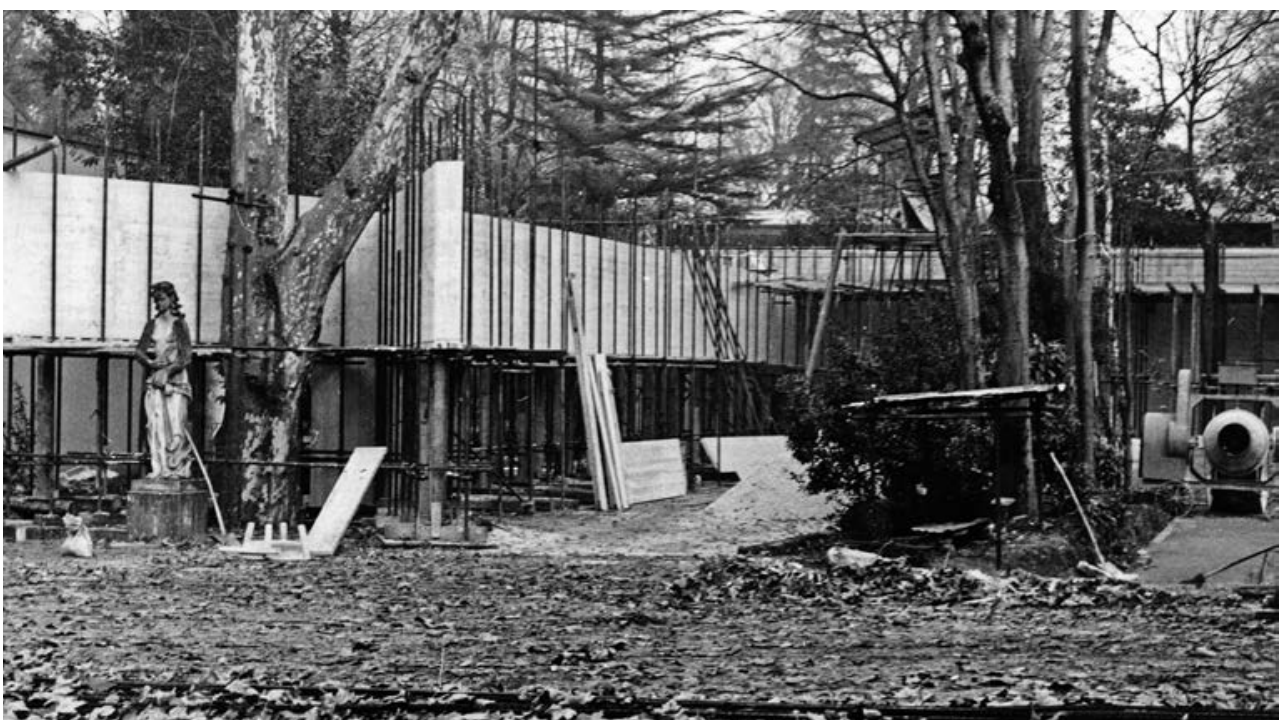

Fehn y Neegard se trasladan a Venecia el 22 de febrero durante la fase de construcción de la cubierta. Se acaba de desencofrar la capa de vigas secundarias sustentantes y se está comenzando a hormigonar la capa superior. Fehn redacta un informe manuscrito en el que traslada a la propiedad que la obra marcha adecuadamente y que el color del hormigón es satisfactorio. Se muestra satisfecho con el resultado: "parece que hemos tenido suerte con la luz". ${ }^{15}$ Toma varias fotografías que muestran las primeras vigas desencofradas y cómo filtran la luz hacia el interior.

Las vigas superiores se encofran y hormigonan sobre la capa inferior, una vez que se han retirado los encofrados laterales de éstas [9]. Los encofrados laterales son los mismos que sirvieron para construir las vigas inferiores. Se comienzan a ejecutar desde la coronación del muro lateral colindante con el pabellón norteamericano [11]. La capa superior de las vigas se replanteó sobre del muro en el que se apoyan; todavía hoy se pueden ver los trazos de grafito sobre el hormigón que indicaban la posición de cada una de ellas.

La obra avanza a buen ritmo. Las baldosas de piedra filita de Oppdal, cuya compra ha gestionado Fehn con la empresa AS Granit, han llegado sin problemas de Noruega y se han instalado en su mayor parte. ${ }^{16}$ También están acabadas las escaleras que, a juicio de Fehn, encajan bien en el entorno y en el camino hacia el pabellón de Checoslovaquia.

Una vez terminada la estructura se colocan los canales de resina de poliéster reforzada con fibra de vidrio de 1,8 $\mathrm{mm}$ de espesor en el entrevigado, sujetos a listones de madera de $6 \mathrm{~cm} \mathrm{x}$ $6 \mathrm{~cm}$. fijados al canto superior de las vigas. Los canales son piezas enteras de forma trapezoidal. Cuando se encajan en el entrevigado de ancho constante forman una diferencia de altura en su seno, lo que genera la pendiente necesaria para desaguar la cubierta. La unión entre el listón de madera y el canal se cubre con una caperuza del mismo plástico que el canal para asegurar la estanqueidad de la junta.

Durante la visita del 10 y 11 de marzo, Fehn y Neegard comprueban que la cubierta está completamente finalizada y se está llevando a cabo la instalación de los canales de plástico translúcido. Informan que la fecha prevista de finalización completa de la cubierta es de un mes. Aprueban favorablemente la fabricación de las peanas que Fehn había diseñado para el espacio expositivo. También están terminadas las puertas correderas de vidrio y pino rojo que componen el cerramiento. Lo fundamental está preparado para la celebración de la exposición Bienal.

La XXXI Bienal tuvo lugar entre el 16 de junio y el 7 de octubre. La recepción provisional no pudo realizarse en marzo como estaba previsto, y se tuvo que simultanear la exposición abierta

15 Informe manuscrito de Fehn a Göran Göransson, 22 de febrero de 1962. Archivo Nacional de Suecia, Riksarkivet sede Marieberg.

${ }^{16}$ En los años 70, se sustituyó el pavimento original por piedra de Istria, debido a la degradación que experimentó el material y los problemas de mantenimiento. 

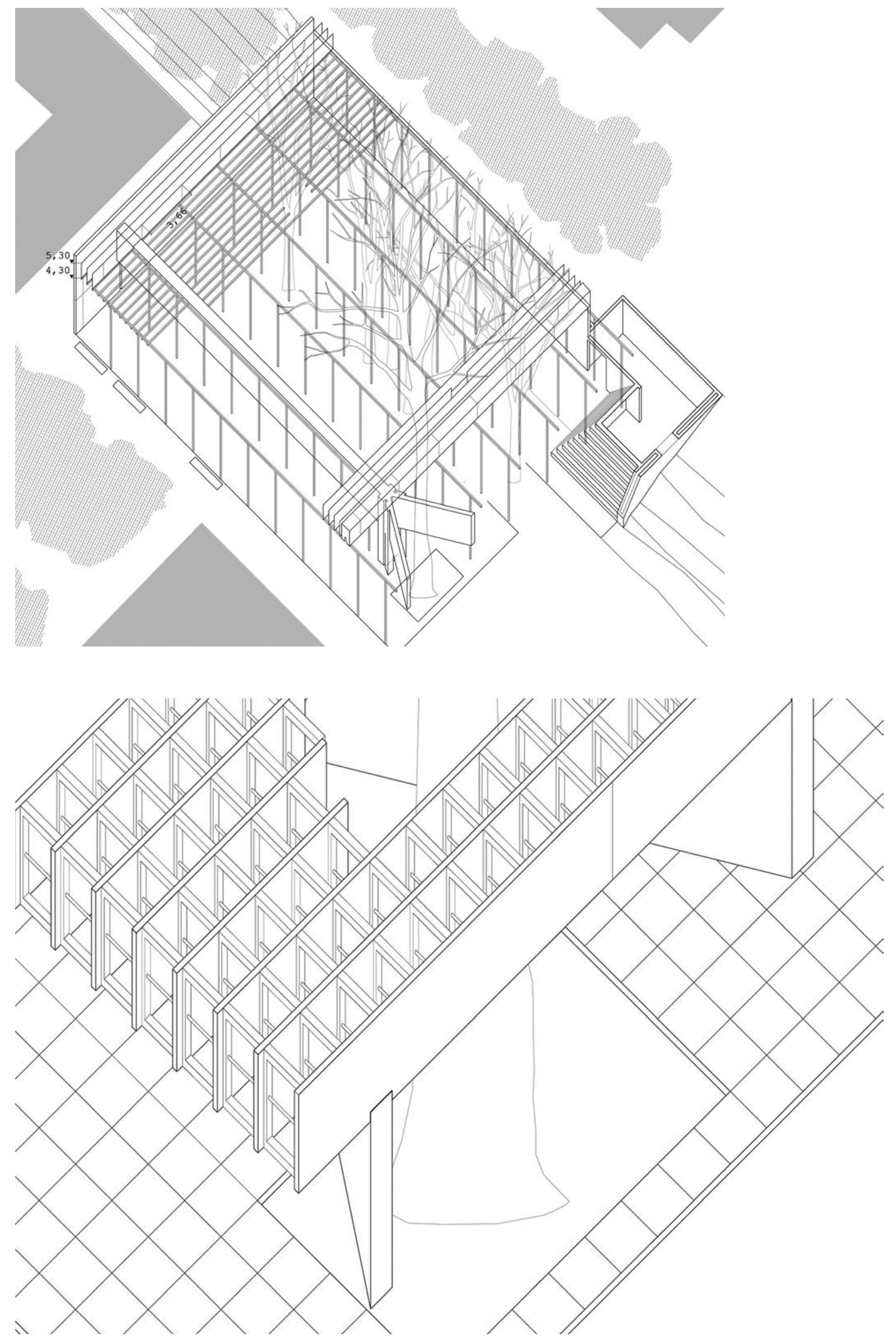

istones de madera apuntalados. Autor: $\mathrm{M}^{\mathrm{a}}$ Dolores Sánchez Moya, 2012.

[9] Detalle de los bastidores que servian para separar las vigas de la capa inferior $y$, al mismo tiempo, como encofrado de la cara inferior de segundo estrato de vigas. Autor: $\mathrm{M}^{\mathrm{a}}$ Dolores Sánchez Moya, 2012.

[10] Una de cada siete vigas de la capa inferior recrece varios centimetros para ofrecer sujeción a las vigas de la capa superior. Autor: Ángel Luis Fernández Campos, 2008.

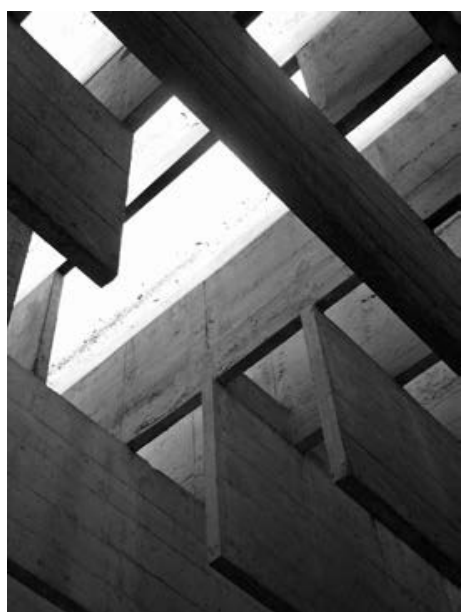

al público, con los trabajos de recalce del Pabellón, cuyo sufrió graves asientos en cuanto la cubierta entró en carga. ${ }^{17}$ La construcción del edificio finalmente supone un gasto de 52,5 millones de liras y la entrega definitiva se demora hasta junio de 1964.

\section{Reciprocidad entre espacio y construcción}

El proceso de la obra ha ido definiendo una arquitectura que nacía a medida que se desencofraban sus elementos. La estructura de la sede nórdica está planteada como un sistema de piezas de hormigón que definen y delimitan el espacio. Estructura y cerramiento coinciden. Ningún elemento se sitúa al margen de este sistema unitario [12]. A lo largo de esta narración se ha descrito una arquitectura de un escaso repertorio material, restringido a cinco componentes: hormigón armado, madera y vidrio, piedra filita y plástico. La construcción se muestra desnuda desde dos puntos de vista: por un lado, los materiales no tienen acabado, se evidencian en su color y textura reales; por otro, el modo en que se traban todos los elementos entre sí es legible. El Pabellón está desprovisto cuanto no está integrado en el mecano de piezas superpuestas.

La filtración de la luz determina la disposición de la materia en el objeto. El espacio del Pabellón puede leerse como el resultado de tres estratos superpuestos de distinta densidad material, establecido por la amortiguación de la intensidad del sol y la equidistribución de la luz al servicio del programa que se desarrolla en el interior. La proporción de masa y vacío varía considerablemente dependiendo del estrato que se esté considerando.

El primero, es el que se encuentra en continuidad con el parque, receptáculo de la claridad que se infiltra por el entramado de vigas. La masa se concentra en un muro perimetral en "L" y un único pilar, formado por cuatro soportes que suman un metro cuadrado de base.

El segundo estrato consiste en una franja virtual delimitada por el canto del dintel. Es aquí donde se percibe la transformación de la luz llevada a cabo por la cubierta. La materia se concentra en el perímetro y el dintel, con dos metros de canto, confina el vacío interior y contribuye a potenciar las cualidades derivadas de la filtración cenital de la luz. Impermeable a la luz y a la visión, su presencia acentúa las cualidades de los dos estratos que separa, por efecto de contraste: opacidad-permabilidad, penumbra-luminosidad, planeidad-textura, estabilidad-movimiento, unicidad-repetición, concentración-atomización, estabilidadvariabilidad.

El último estrato es el definido por la cubierta, donde la proporción de masa crece extraordinariamente, se reparte de forma homogénea en toda la superficie y el vacío queda confinado al intersticio entre las vigas [13]. La cubierta está extraordinariamente atomizada: las vigas se repiten formando una tupida trama. Parece como si se hubieran reunido en la cuadrícula el máximo número posible de elementos.

Los elementos que componen el sistema constructivo presentan importantes diferencias dimensionales entre sí dependiendo no tanto de su naturaleza sustentante o sustentada como del fin al que sirvan: alojamiento del programa o filtración de la luz. Estos elementos antagónicos están construidos con un mismo material -hormigón in situ- e integrados en un sistema constructivo que enfatiza su diferencia. La sintaxis constructiva de piezas apiladas y la solución de sus uniones es más propia de la prefabricación o de la construcción en madera que del hormigón vertido, y otorga una independencia formal de los elementos que componen la estructura. Como ya se ha mencionado, durante la definición del proyecto, Fehn planteó la posibilidad de un sistema constructivo de hormigón prefabricado. Probablemente el sistema constructivo del Pabellón sea consecuencia de esta primera intención, así como del bagaje arquitectónico de Fehn: la construcción vernácula noruega en madera, de la que el propio Fehn comenta "aquí talamos un árbol y lo colocamos de forma horizontal. Las piezas de madera en la casa tradicional noruega simplemente descansan unas sobre otras".18

Todas estas consideraciones ponen de manifiesto que el aspecto que establece esta intensa correspondencia entre espacio y construcción reside en la acción de filtrar la luz. La cubierta filtro no solo produce un tipo de luz difusa adecuada para el espacio expositivo sino que dimensiona y proporciona el espacio, organiza la materia, determina el sistema constructivo y es esencial al orden interno de la obra.

\footnotetext{
${ }^{17}$ El pilar se hundia a un ritmo de $2 \mathrm{~mm}$ por semana. La empresa Italsonda recalza la cimentación con veintidós pilotes de 15 metros de longitud cada uno. El recalce se confía a la empresa especializada en cimentaciones Italsonda. Los trabajos se llevan a cabo en un área de seguridad acordonada alrededor del pilar, para que no interfiera con las visitas a la exposición. Se ejecutan un total de treinta y seis micropilotes alrededor del pilar con hormigón inyectado a alta presión a una profundidad de 18 metros. En octubre de 1962 se realiza una prueba de carga que la nueva cimentación supera satisfactoriamente. El pilar ha descendido ocho centímetros en tres meses. Fredik Fogh encuentra que este es el aspecto más negativo del edificio: la decisión de trasladar una buena parte de la carga de la cubierta y el dintel a un único soporte.

${ }^{18}$ En Mathilde Petri; “Da Sverre Fehn”, Skala n²3, 1990, págs 12-17. En esta descripción Fehn hace referencia a las dos formas tradicionales de construcción noruega en madera: log y stave.
} 

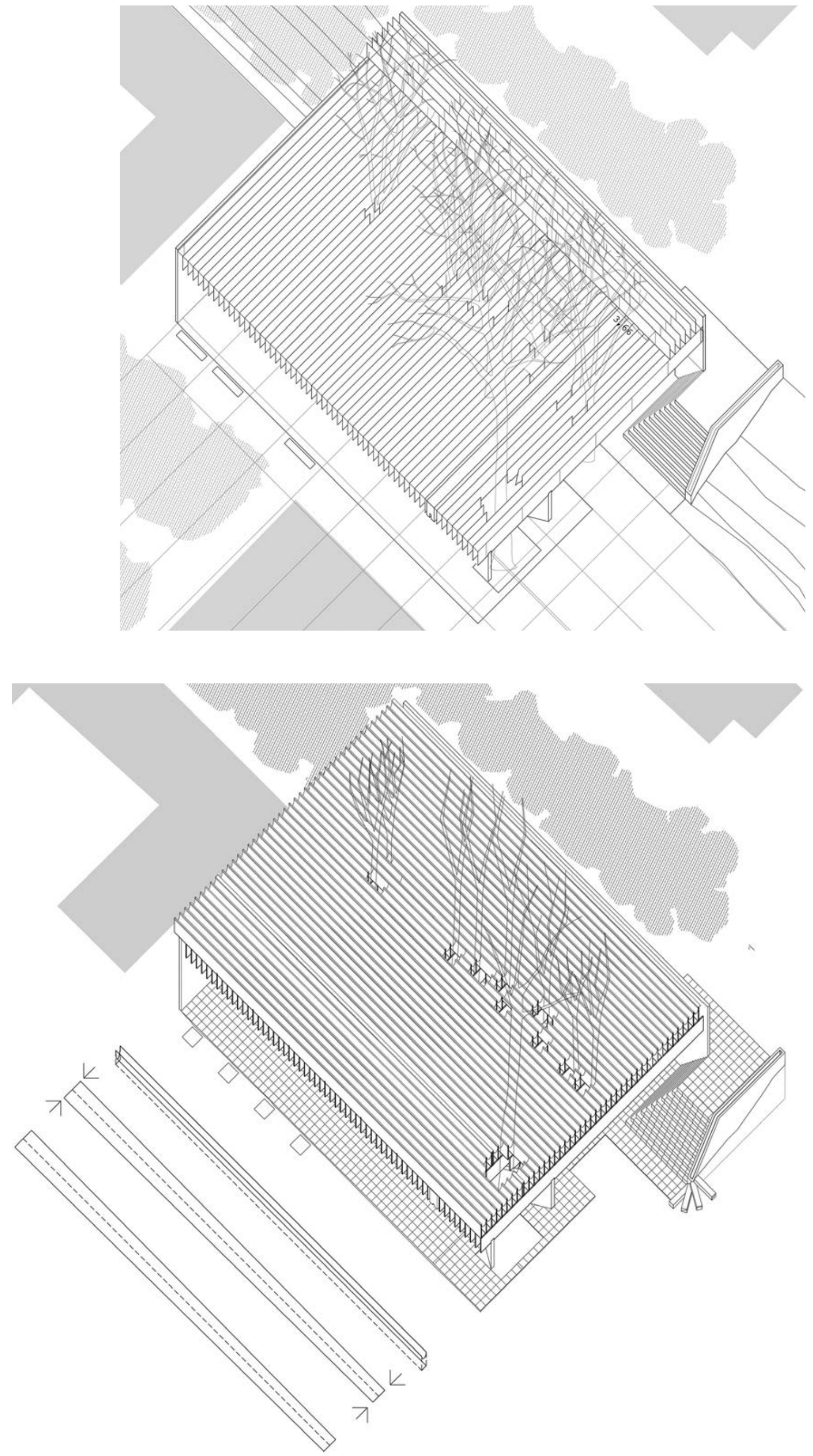


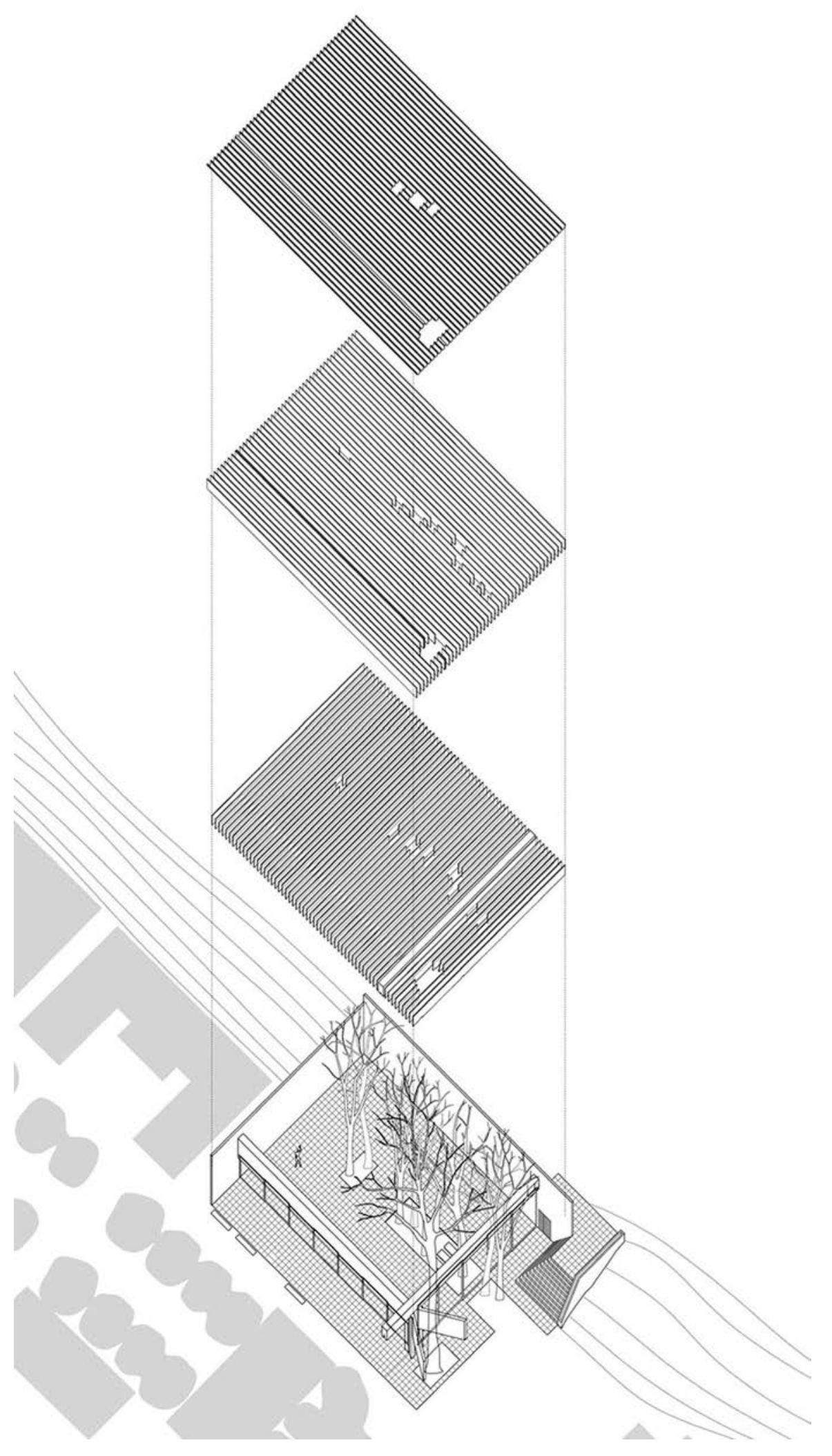

[12] Los canales se fabricaron con piezas enteras de resina de poliéster de forma trapezoidal, de manera que al encajarse en el entrevigado, variab su sección para facilitar el desagüe. Autor: M Dolores Sánchez Moya, 2012.

[13] El Pabellón como mecano de piezas superpuestas. Autor: Mª Dolores Sánchez Moya,
2012. 